\title{
Atypical Presentation of Invasive Mole in a Young Female with Chemo resistance Case Report and Review of Literature
}

\author{
Rajshree Dayanand Katke ${ }^{1 *}$ and Nishtha Tripathi ${ }^{2}$ \\ ${ }^{1}$ Professor, Medical supritendent Cama Albless hospital, India \\ ${ }^{2} J u n i o r$ resident department of obstetrics and gynecology, Grant government medical college, India
}

Submission: January 04, 2017; Published: January 30, 2017

*Corresponding author: Rajshree Dayanand Katke, Medical suprintendent Cama Albless hospital, India, Email: drrajshrikatke@gmail.com

\begin{abstract}
Gestational trophoblastic neoplasias (GTN) are rare tumours that constitute less than $1 \%$ of all gynecological malignancies. Invasive mole is a condition where a molar pregnancy, such as a partial hydatidiform mole or complete hydatidiform mole, invades the wall of the uterus, potentially spreading and metastasizing to other parts of the body. Invasive mole is a distinct subgroup of GTN, which if not diagnosed and treated early, can result in serious complications like uterine perforation and haemoperitoneum. We present a rare case of anchemoresistant invasive mole of the uterus, which developed following the evacuation of a molar pregnancy. It was accurately diagnosed and successfully treated before any major complications could arise.
\end{abstract}

Keywords: Complete hydatiform mole; Invasive mole; Beta-human chorionic gonadotropin; Haemoperitoneum; Chemoresistant

\section{Introduction}

Gestational Trophoblastic Disease (GTD) is an umbrella term for a group of pregnancy related disorders arising from abnormal placental trophoblast cells. It encompasses two premalignant conditions: partial and complete hydatidiform moles and the malignant Gestational Trophoblastic Neoplasias (GTN). GTNs are classified histologically into three distinct subgroups: choriocarcinomadestruens (invasive mole), choriocarcinoma (CC) and the very rare placental site trophoblastic tumor (PSTT) [1]. Invasive moles are responsible for most cases of localized GTN. Invasive moles have high potential of metastasizing and local invasion causing hemoperitoneum Invasive mole is condition where a molar pregnancy invades the wall of the uterus. It follows approximately $10-15 \%$ of complete hydatidiform moles and $0.5 \%$ of patients with partial mole [2]. For Invasive mole the imaging of choice is B-mode ultrasonography and color Doppler. When ultrasonography corresponds with the classical clinical presentation, an accurate diagnosis is possible in a majority of cases. With early and accurate diagnosis, the cure rate is high. Treatment of an invasive mole may include both chemotherapy and surgery.

\section{Case Report}

28 years old Female, gravida three para one living one abortion one with previous ceasearian section came to our OPD with the chief complaints of two months of amenorrhea with bleeding per vaginum since one day and with ultrasonography report suggestive of vesicular mole. By last menstrual period patient has 9 weeks of gestation. On general examination patient was vitally stable (Figure 1-3).

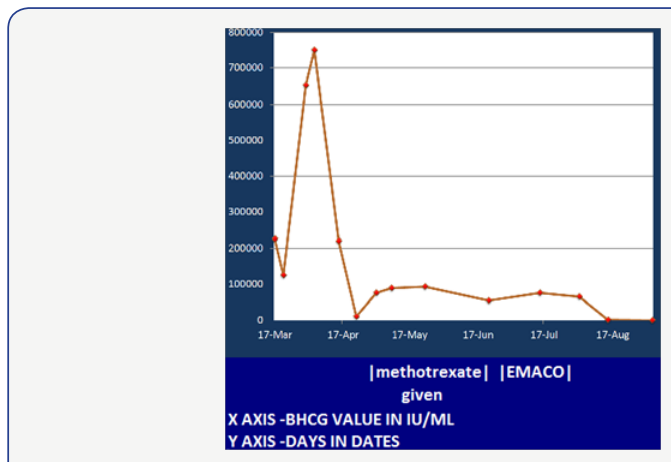

Figure 1: B-HCG Graph According To Treatment. 


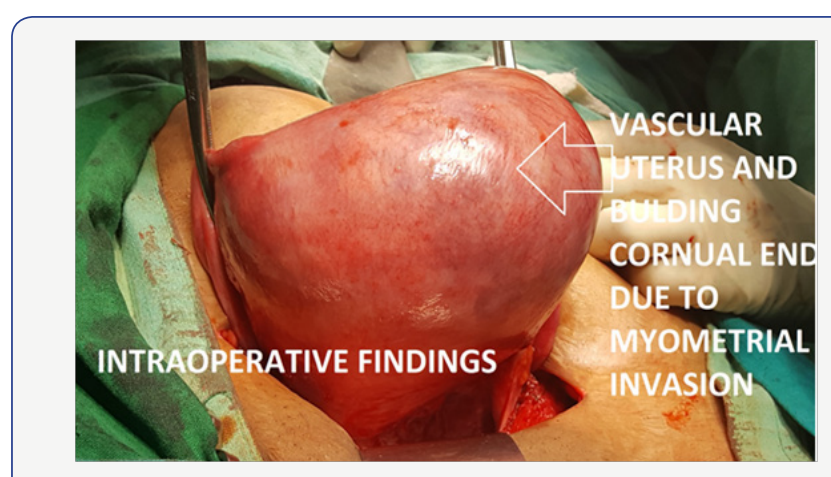

Figure 2: Intraoperative picture suggestive of buldging of right cornua due to invasion on the same side.

Figure 3: Gross specimen showing irregular shape of uterus
due to shape of uterus.

On per abdominal examination abdomen was soft and patient was obese there was no guarding tenderness or rigidity. On per speculum spotting was present and on per vaginum uterus was 12-14 weeks size and cervical os was closed. Patient all routine, serum beta human chorionic gonadotropin, ecg, xray, thyroid function test was done immediately. Her Serum beta human chorionic gonadotropine (beta hCG) was 225000 IU. Her all routine and thyroid function test was within normal limits. Chest $\mathrm{x}$-ray was normal. Patient was taken for suction evacuation. Repeat B-hcg was done on day 3 post suction evacuation was $125000 \mathrm{IU} / \mathrm{ML}$. Patient took discharge and again follow up after one week with complaint of spotting per vaginum and fresh beta-hcg report with value of 750000 IU. We have done urgent ultrasound of the patient which was suggestive of hyadatiform mole? invasion asendomyometrial junction is not well demarcated. We started patient on single agent chemotherapy. After one cycle serum beta hcg was repeated and was $225000 \mathrm{iu}$ $/ \mathrm{ml}$. Repeat ultrasound was done suggestive of decrease in size of uterus since previous scan residual lesion is still significant with well defined endimyometrial junction. Hence decision of repeat suction evacuation was done.

Repeat serum beta-hcg was less than $10000 \mathrm{iu} / \mathrm{ml}$. But still for safer practice we have done repeat ultrasound for the patient which shows residual mole invading the myometrium and repeat serum beta hcg also raised to 75000 from 10000 iu. Patient was started on EMACO REGIMEN. three cycle of EMACO regimen was given. HRCT SCAN was done and was normal. Patient's serum beta hcg was repeated and there was no significant change in the beta hcg values. MRI was done and was suggestive of multicystic lesion of size $8.7 \times 6.3 \times 7 \mathrm{~cm}$ septate involving myometrium s/o invasive mole with no extrauterine spread and no lymphadenopathy. There was no significant decrease in size of lesion and serum b hcg level even after three cycles of EMACO regimen. Hence tough decision hysterectomy was done in view of chemoresistant invasive persistent trophoblastic disease. Her post operative period was uneventful.post operative value of serum betahcg was $165 \mathrm{iu} / \mathrm{ml}$. patient was discharge on post operative day 7. Patient last follow up serum bhcg was $4 \mathrm{iu} / \mathrm{ml}$.

\section{Discussion}

Gestational trophoblastic neoplasia, 60\% was secondary to hydatidiform mole, $30 \%$ to abortion, and $10 \%$ secondary to full term pregnancy or ectopic pregnancy. According to the epidemiological retrospective survey, invasive mole was diagnosed as secondary to hydatidi form mole emptying within half a year and choriocarcinoma was mostly more than a year. Clinical manifestations of GTN involve full-term vaginal bleeding after childbirth, ectopic pregnancy and (or) corresponding signs and symptoms of metastatic organs [3].

CT, MRI, biopsy, blood HCG test, cystoscope, and laparoscopic examination are typically used as evaluation means and methods. Histological diagnosis is the gold standard, but sometimes we can only based on clinical diagnosis without histological evidence. Gestational trophoblastic tumor is typically sensitive to chemotherapy, and the cure rate about $80 \%$ to $90 \%$. International Federation of Gynecologists and Obstetricians (FIGO) found prognostic scoring system in which gestational trophoblastic tumors are divided into low-risk and high-risk groups [4].

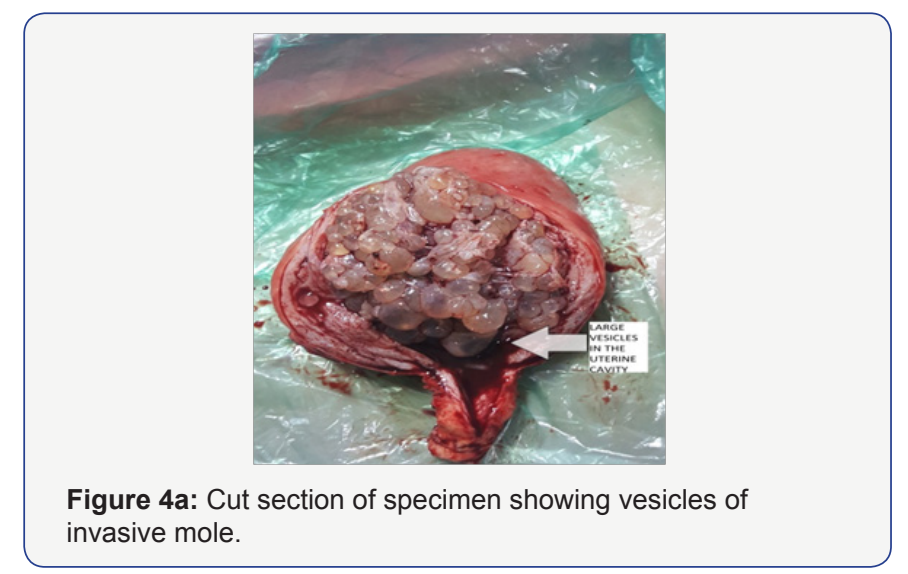

Patients in low-risk group, generally are carried with single-agent chemotherapy such as Methotrexate (MTX) or actinomycin D treatment, while the high-risk group with multi-drug chemotherapy regimens, and EMA-CO is commonly used chemotherapy regimens [5]. As in our case the diseases progresses very rapidly and was almost progressed uptoserosa, hence increases chances of metastasis, perforation, acute hemoperitoneum etc. Preoperative X-ray chest hemogram, 
baseline B-HCG, blood grouping, liver enzymes done routinely before suction Evacuation (Figure 4a-4c).
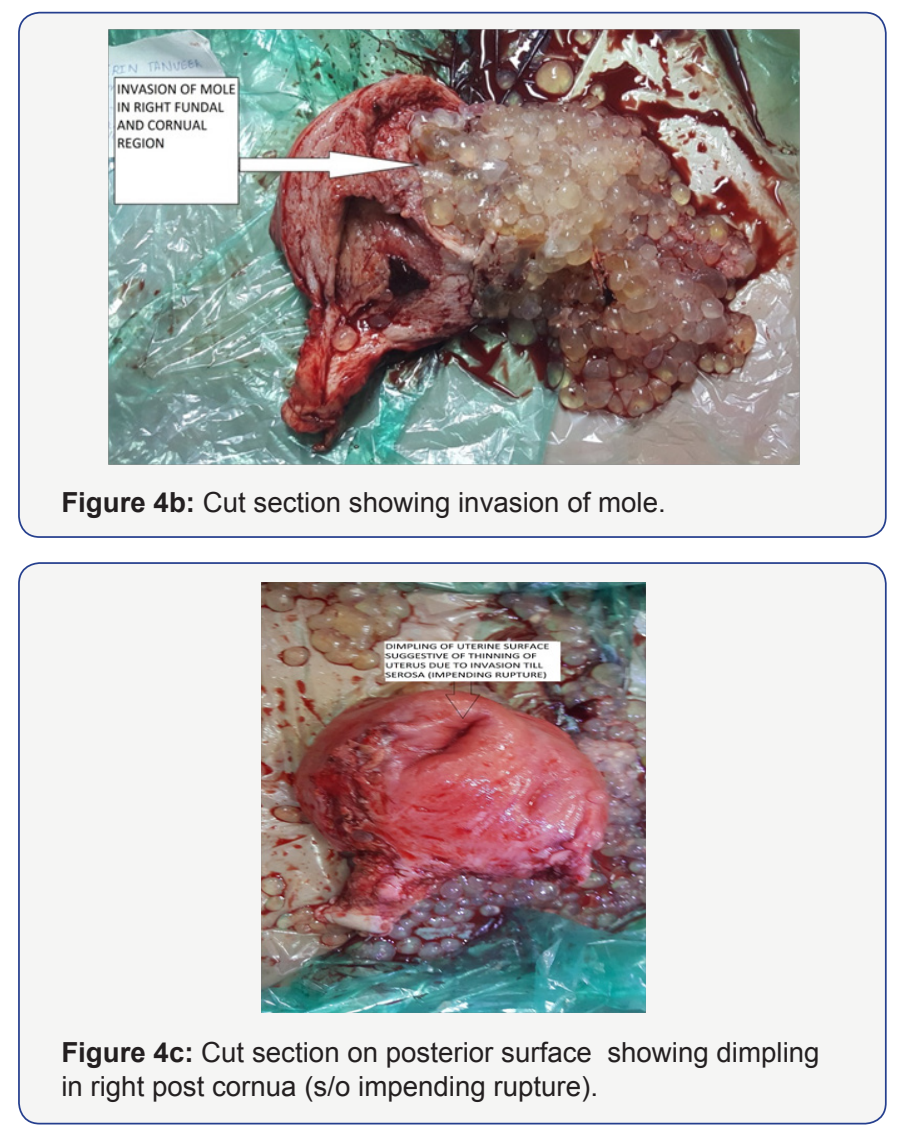

It is also an important adjunct to the treatment of chemoresistant tumors. Chemotherapy is now the established method of treatment of choriocarcinoma and hysterectomy and surgical resection of the tumor is rarely required in cases resistant to chemotherapy [6]. In summary, GTN as a curable tumor, even if resistance, and its general principle of treatment is to cure and not just to prolong survival time. To patients at high risk and chemoresistance, we should emphasize the extent of disease and the previous treatments, to develop individualized treatment programs. In addition, we should also emphasize the important of surgical treatment, take a comprehensive assessment of the patient's condition, apply chemotherapy actively, fight for surgical resection resistant lesions, in order to achieve the ultimate goal of sustained remission. Continuous monitoring blood HCG levels [7] and imaging examination [8], both of which are available methods to determine GTN therapeutic effect and recurrence.

\section{Conclusion}

Our case report emphasizes that persistent trophoblastic disease needs to be defined precisely and early diagnosis and treatment. Chemoresistant invasive mole surgical intervention at proper time in management of persistent trophoblastic disease is the key to $100 \%$ survival in gestational trophoblastic neoplasia. Furthermore, early diagnosis by ultrasound and histopathological examination is the key to avoid associated complications such as acute hemoperitoneum, perforation metastasis, hyperemesis gravidarum, hyperthyroidism, and preeclampsia. Our case also proves that there is complete remission with no metastasis of chemoresistent invasive mole if early diagnosis and correct decision of appropriate treatment is done.

\section{References}

1. Ngan HY, Bender H, Benedet JL, Jones H, Montruccoli GC, et al (2003) Gestational trophoblastic neoplasia, FIGO 2000 staging and classification. Int J Gynaecol Obstet 83(Suppl 1): 175-177.

2. Hammond CB (1999) Gestational trophoblastic neoplasms. In: Scott JR, Di Saia PJ, et al. (Eds), Danforth's Ob- 178 Kavitha Nair et al Invasive mole of the uterus - a rare case diagnosed by ultrasound: a case report stetrics and Gynecology, ( $8^{\text {th }}$ edn), Lippincott Williams \& Wilkins, Philadelphia, USA, pp. 927-937.

3. Ngan S, Seckl MJ (2007) Gestational trophoblastic neoplasia management: an update. Curr Opion Oncol 19(5): 486-491.

4. EL-Helw LM, Hancock BW (2007) Treatment of metastatic gestational trophoblastic neoplasia. Lancet Oncol 8(8): 715-724.

5. Deng L, Zhang J, Wu T, Lawrie TA (2013) Combination chemotherapy for primary treatment of highrisk gestational trophoblastic tumour. Cochrane Database Syst Rev 1: CD005196.

6. Katke RD (2015) Atypical presentation of uterine choriocarcinoma a case report with review of literature. Clin Cancer Investig J 4(6): 713716.

7. You B, Pollet-Villard M, Fronton L, Labrousse C, Schott AM, et al. (2010) Predictive values of hCG clearance for risk of methotrexate resistance in low-risk gestational trophoblastic neoplasias. Ann Oncol 21(8): 1643-1650.

8. Cavoretto P, Gentile C, Mangili G, Garavaglia E, Valsecchi L, et al. (2012) Transvaginal ultrasound predicts delayed response to chemotherapy and drug resistance in stage I low-risk trophoblastic neop- lasia. Ultrasound Obstet Gynecol 40(1): 99-105. 
Your next submission with Juniper Publishers will reach you the below assets

- Quality Editorial service

- Swift Peer Review

- Reprints availability

- E-prints Service

- Manuscript Podcast for convenient understanding

- Global attainment for your research

- Manuscript accessibility in different formats ( Pdf, E-pub, Full Text, Audio)

- Unceasing customer service

Track the below URL for one-step submission https://juniperpublishers.com/online-submission.php 